\title{
PERBANDINGAN METODE SOMOGYI-NELSON DAN ANTHRONE-SULFAT PADA PENETAPAN KADAR GULA PEREDUKSI DALAM UMBI CILEMBU (Ipomea batatas L.)
}

\author{
Hasanul Kiyan Al-kayyis, Hari Susanti*) \\ Fakultas Farmasi, Universitas Ahmad Dahlan, Yogyakarta, Indonesia
}

Received May 23, 2016; Accepted August 15, 2016

\begin{abstract}
Sweet potato cultivar Cilembu, kind of 'rancing' from Cilembu Village, Sumedang, West Java has really sweet taste due to the high content of reducing sugar. The amount of reducing sugar needs to be proven scientifically. The study aimed to compare Somogyi-Nelson method and Anthrone-Sulfate method in order to determine reducing sugar level in Cilembu sweet potato. Cilembu sweet potato must be stored in freezer at $15^{\circ} \mathrm{C}$ for 2 weeks before used as the sample. Analytical method validation was performed for the two methods. The determination results between two methods were compared. The amount of reduction sugar (glucose) from Cilembu sweet potato determined by Somogyi-Nelson method was 3.42\%, the value of \%recovery was 99.8\%, LOD $=0.00167(\mathrm{mg} / \mathrm{mL}), L O Q=0.00557(\mathrm{mg} / \mathrm{mL})$, and value of RSD was $3.7 \%$. While the average amount of reduction sugar determined by Anthrone-Sulfate method was 14.9\%, the value of \%recovery was $74.7 \%, L O D=0.0198(\mathrm{mg} / \mathrm{mL}), L O Q=0.066(\mathrm{mg} / \mathrm{mL})$, and value of $R S D=$ 8.6\%. The Somogyi-Nelson method was more recommended for the analysis of the reducing sugar in Cilembu sweet potato compared with Anthrone-Sulfate method.
\end{abstract}

Keyword: Sweet potato, Cilembu, Somogyi-Nelson, Anthrone-Sulfate

\section{PENDAHULUAN}

Ubi-ubian merupakan salah satu kekayaan sumberdaya hayati indonesia yang sangat potensial untuk dikembangkan terutama dalam upaya mewujudkan ketahanan pangan nasional (Ambarsari et al., 2009). Salah satu contohnya adalah ubi jalar kultivar Cilembu jenis rancing yang memiliki kelebihan dari segi rasa dan ekonomis ini, serta ketahanannya dalam proses penanaman dari hama dan penyakit tanaman.

Beberapa tahun belakangan ini ubi Cilembu atau ubi madu dikalangan masyarakat Sumedang, Jawa Barat, dijadikan sebagai kudapan karena rasanya yang enak, manis, dan teksturnya yang lembut. Secara umum, rasa manis dari ubi jalar diperoleh melalui proses penguraian karbohidrat (pati) oleh enzim amilase menjadi gula (Zhang et al., 2002). Gula yang dihasilkan dari proses penguraian tersebut adalah glukosa, sukrosa dan fruktosa. Jenis gula inilah yang menentukan rasa manis dari tiap jenis ubi jalar. Rasa manis pada ubi Cilembu berkorelasi dengan jumlah gula yang ada, terutama gula pereduksinya (glukosa, fruktosa)
(Mayastuti, 2002). Namun, jumlah gula pereduksi yang ada dalam ubi Cilembu ini perlu dibuktikan secara ilmiah. Pembuktian dapat dilakukan dengan menggunakan analisa penetapan kadar gula, seperti metode Somogyi-Nelson, dan metode anthronesulfat.

Metode Somogyi-Nelson merupakan metode penetapan kadar gula pereduksi, dimana prinsipnya, gula pereduksi akan mereduksi ion $\mathrm{Cu}^{2+}$ menjadi ion $\mathrm{Cu}^{+}$, kemudian ion $\mathrm{Cu}^{+}$ini akan mereduksi senyawa arsenomolibdat membentuk kompleks berwarna biru kehijauan (Nelson, 1944). Sedangkan untuk metode anthrone-sulfat, merupakan metode penetapan gula total, dimana prinsipnya, gula pereduksi atau non pereduksi akan bereaksi dengan asam sulfat pekat membentuk furfural atau turunannya, kemudian furfural tadi akan bereaksi membentuk kompleks berwarna kuning kehijauan dengan reagen anthrone (Koehler, 1952). Berdasarkan teori metode Somogyi-Nelson lebih spesifik jika digunakan dalam penetapan kadar gula pereduksi pada sampel 
yang memiliki senyawa gula campuran di dalamnya, dibandingkan metode anthrone-sulfat.

Dari latar belakang yang ada, permasalahan yang bisa diangkat tidak hanya tentang pembuktian kadar gula pereduksinya saja yang dapat dilakukan tetapi juga pembuktian terhadap metode yang lebih baik dan lebih disarankan untuk digunakan dalam analisa kadar gula pereduksi ubi Cilembu. Pembuktian metode ini dilakukan dengan uji validasi (Akurasi, Presisi, LOD, LOQ).

\section{METODE PENELITIAN}

\section{Bahan dan Alat}

Bahan-bahan yang digunakan ubi Cilembu jenis Rancing dengan pemeraman selama 2 minggu di dalam freezer suhu $15^{\circ} \mathrm{C}$ dengan rentang 200400 gram, reagen Anthrone-Sulfat, reagen Nelson A dan B, reagen arsenomolibdat, reagen barfoed, reagen benedict, reagen molisch serta standar Glukosa p.a Merck.

Alat yang digunakan Centrifuge PCL series, Halogen Moisture HB 43, neraca analitik (Mettler Toledo), Ayakan no. 80, Magnetic Stirrer, Vakum + Corong Buchner, Tanur, dan Spektrofotometer UV 1700 Shimadzu Pharmaspec Uv-Vis.

\section{Identifikasi Tanaman}

Identifikasi terhadap tanaman dilakukan di Laboratorium Biologi Fakultas Matematika dan Ilmu Pengatahuan Alam Universitas Ahmad Dahlan Yogyakarta.

\section{Pembuatan Simplisia (Tepung)}

Ubi Cilembu segar dibersihkan dan dikupas kulitnya, kemudian ubi diiris dengan menggunakan slicer dengan ketebalan $1 \mathrm{~mm}$. Selanjutnya irisan Ubi dikeringkan dalam oven pengering suhu $55^{\circ} \mathrm{C}$ selama 10 jam hingga irisan Ubi dapat dipatahkan dengan tangan. Irisan Ubi kemudian digiling dengan blender dan diayak dengan ayakan ayakan no. 80 sampai lebih dari $90 \%$ tepung lolos ayakan.

\section{Standarisasi Simplisia \\ Uji organoleptis}

Uji organoleptis dilakukan dengan melihat warna, mencium baud an mencicipi rasa tepung ubi Cilembu.

\section{Uji Kadar Abu Total}

Penetapan Kadar Abu Total dilakukan dengan cara memasukkan simplisia yang telah ditimbang sebanyak lebih kurang 3 gram, lalu dimasukkan ke dalam krus platina dan dipijarkan di dalam tanur suhu $600^{\circ} \mathrm{C}$ sampai bobot konstan selama 6 jam. (Anonim, 2008).

\section{Uji Kadar Air}

Ke dalam labu kering dimasukkan lebih kurang 5,0 gram simplisia, kemudian tambahkan $200 \mathrm{~mL}$ toluen $\mathrm{p}$ kedalam labu, hubungkan alat destilasi. Panaskan labu hati-hati selama 15 menit setelah toluen mulai mendidih suling dengan kecepatan kurang lebih 2 tetes tiap detik, hingga sebagian besar air tersuling. Lanjutkan penyulingan selama 5 menit. Biarkan tabung penerima mendingin hingga suhu kamar. Setelah air dan toluen memisah sempurna, baca volume air. Hitung kadar air dalam persen (Anonim, 2008).

\section{Uji Susut Pengeringan}

Pemeriksaaan kadar susut pengeringan dengan menggunakan Halogen Mouisture Analyzer. (Anonim, 2008).

\section{Ekstraksi}

Menimbang seksama 5,0 gram tepung Ubi Cilembu kemudian dicampur dengan $90 \mathrm{~mL}$ air mendidih sambil diaduk dan $\mathrm{pH}$ diatur pada kisaran 6,5-8 dengan menambahkan 0,05 $\mathrm{N} \mathrm{KOH}$ atau 0,05 $\mathrm{N}$ HCl. Kemudian ekstrak dipanaskan sambil diaduk menggunakan magnetic stirrer $(600 \mathrm{rpm})$ pada suhu $\left(85^{\circ} \mathrm{C} \pm 2\right)^{\circ} \mathrm{C}$ selama 10 menit (Anonim,1999). Larutan ekstrak kemudian disaring dengan menggunakan corong Buchner kemudian larutan disentrifuge ambil fase bagian atas. Fase cair diambil kemudian dipindahkan ke dalam labu takar $100 \mathrm{~mL}$ dan ditera mencapai $100 \mathrm{~mL}$.

\section{Uji Kualitatif Gula dalam Ubi Cilembu Uji Molisch}

Sebanyak $1 \mathrm{~mL}$ sampel hasil ekstraksi ditambahkan $3 \mathrm{~mL} \mathrm{H}_{2} \mathrm{SO}_{4} \mathrm{p}$, kemudian tambahkan $1 \mathrm{~mL}$ pereaksi Molisch ( $\alpha$-naftol dalam Etanol $96 \%$ ) campur dengan baik. Jika terbentuk cincin 
berwarna ungu, maka sampel positif mengandung gula (Poedjiadi, 2009).

\section{Uji Benedict}

Satu $\mathrm{mL}$ larutan sampel hasil ekstraksi ditambahkan reagen Benedict, gojok. Kemudian larutan didihkan dengan menggunakan api kecil dan dinginkan perlahan-lahan. Hasil akhir yaitu terbentuk endapan merah bata jika sampel mengandung gula pereduksi (Poedjiadi, 2009).

\section{Uji Barfoed}

Satu mL larutan sampel hasil ekstraksi ditambahkan pereaksi Barfoed campur dengan baik. Larutan didihkan dengan api kecil, perhatikan endapan merah yang terbentuk dan catat waktu pembentukannya (Poedjiadi, 2009).

\section{Kromatografi Lapis Tipis (KLT)}

Larutan ekstrak dan larutan pembanding (standar Glukosa, Fruktosa, Sukrosa, Laktosa, galaktosa pada konsentrasi $0,2 \mathrm{mg} / \mathrm{mL}$ ) masingmasing ditotolkan menggunakan pipa kapiler pada fase diam, plat silika gel G. Selanjutnya dielusi menggunakan fase gerak etil asetat-isopropanolair-piridin (26:14:10:2, v/v). Setelah elusi selesai, plat disemprot dengan aniline-difenilamin dan dimasukkan ke dalam oven suhu $55^{\circ} \mathrm{C}$ selama 5 menit untuk membuat noda menjadi tampak.

\section{Uji Kuantitatif (Anthrone-Sulfat)}

Penentuan OT, $\lambda$ maks, dan kurva baku Standar (Anonim, 1999)

Penentuan OT dilakukan dengan menambahkan 1,0 mL larutan standar glukosa konsentrasi $0,06 \mathrm{mg} / \mathrm{mL}$ ) dengan $5 \mathrm{~mL}$ pereaksi anthrone di dalam lemari asam. Kemudian tutup tabung dan gojok larutan agar tercampur rata. Larutan kemudian dipanaskan di atas waterbath dengan suhu $100^{\circ} \mathrm{C}$ selama 12 menit, yang dibaca pada lamda $630 \mathrm{~nm}$ selama 1 jam.

Penentuan panjang gelombang absorbansi maksimum dilakukan dengan menambahkan $1 \mathrm{~mL}$ larutan standar glukosa konsentrasi $0,06 \mathrm{mg} / \mathrm{mL}$ dengan $5 \mathrm{~mL}$ pereaksi anthrone di dalam lemari asam. Kemudian tutup tabung dan gojok larutan agar tercampur rata. Larutan kemudian dipanaskan di atas waterbath dengan suhu $100^{\circ} \mathrm{C}$ selama 12 menit, tunggu hingga OT yang diperoleh sebelumnya, baca absorbansi rentang panjang gelombang $580-680 \mathrm{~nm}$.

Penentuan kurva baku dilakukan dengan menambahkan 1,0 mL larutan standar glukosa konsentrasi 0 (lar. blanko); 0,02; 0,04; 0,06; 0,08; 0,$1 ; 0,12(\mathrm{mg} / \mathrm{mL})$ dengan $5 \mathrm{~mL}$ pereaksi anthrone di dalam lemari asam. Kemudian tutup tabung dan gojok larutan agar tercampur rata. Larutan kemudian dipanaskan di atas waterbath dengan suhu $100^{\circ} \mathrm{C}$ selama 12 menit, setelah itu didinginkan dan ditunggu hingga OT yang didapat sebelumnya. Kemudian larutan dibaca sereapannya di spektrofotometer visible pada panjang gelombang maks yang didapat $(623,8$ $\mathrm{nm})$.

\section{Penetapan Kadar Glukosa Ubi Cilembu dengan metode Antrone-Sulfat. (Anonim, 1999)}

Penetapan kadar glukosa dalam ubi Cilembu dilakukan dengan menambahkan $1 \mathrm{~mL}$ larutan ekstrak sampel konsentrasi $0,2 \mathrm{mg} / \mathrm{mL}$ dengan 5 $\mathrm{mL}$ pereaksi anthrone di dalam lemari asam. Kemudian tutup tabung dan gojok larutan agar tercampur rata. Larutan kemudian dipanaskan di atas waterbath dengan suhu $100^{\circ} \mathrm{C}$ selama 12 menit, setelah itu didinginkan dan ditunggu hingga OT yang didapat sebelumnya. Kemudian larutan dibaca absorbansinya di spektrofotometer visible pada panjang gelombang maks yang didapat $(623,8 \mathrm{~nm})$.

\section{Uji Kuantitatif (Somogyi-Nelson)}

\section{Penentuan OT, $\lambda$ maks, dan kurva baku Standar} (Nelson, 1944)

Penentuan OT dilakukan dengan menambahkan $1 \mathrm{~mL}$ larutan standar glukosa konsentrasi $0,04 \mathrm{mg} / \mathrm{mL}$ dengan $1,0 \mathrm{~mL}$ reagen $\mathrm{Cu}$ alkalis (Campuran reagen Nelson A dan B). Kemudian larutan digojok dan larutan dipanaskan di atas waterbath dengan suhu $100^{\circ} \mathrm{C}$ selama 20 menit. Kemudian larutan digojok dan larutan dipanaskan kembali di atas waterbath dengan suhu $100^{\circ} \mathrm{C}$ selama 10 menit. Larutan ditambah $\mathrm{NaOH}$ $1 \mathrm{~N}$ sebanyak $\pm 4 \mathrm{~mL}$ sampai $\mathrm{pH}$ larutan $7-8$. Baca absorbansi pada lamda 740nm selama 1 jam. 
Penentuan panjang gelombang absorbansi maksimum dilakukan dengan menambahkan $1 \mathrm{~mL}$ larutan standar glukosa konsentrasi $0,04 \mathrm{mg} / \mathrm{mL}$ dengan 1,0 $\mathrm{mL}$ reagen $\mathrm{Cu}$ alkalis (Campuran reagen Nelson A dan B). Kemudian larutan digojok dan larutan dipanaskan di atas waterbath dengan suhu $100^{\circ} \mathrm{C}$ selama 20 menit. Kemudian larutan digojok dan larutan dipanaskan kembali di atas waterbath dengan suhu $100^{\circ} \mathrm{C}$ selama 10 menit. Larutan ditambah $\mathrm{NaOH} 1 \mathrm{~N}$ sebanyak $\pm 4 \mathrm{~mL}$ sampai $\mathrm{pH}$ larutan 7-8. Tunggu hingga waktu OT yang diperoleh. Baca absorbansi pada rentang panjang gelombang 640-840 nm.

Pembacaan kurva baku dilakukan dengan menambahkan $1 \mathrm{~mL}$ larutan standar glukosa konsentrasi 0 (lar. blanko); 0,025; 0,03;0,035; $0.04 ; 0,045 ; 0,05 ; 0,055(\mathrm{mg} / \mathrm{mL})$ dengan $1,0 \mathrm{~mL}$ reagen $\mathrm{Cu}$ alkalis (Campuran reagen Nelson $\mathrm{A}$ dan B). Kemudian larutan digojok dan larutan dipanaskan di atas waterbath dengan suhu $100^{\circ} \mathrm{C}$ selama 20 menit. Kemudian larutan digojok dan larutan dipanaskan kembali di atas waterbath dengan suhu $100^{\circ} \mathrm{C}$ selama 10 menit. Larutan ditambah $\mathrm{NaOH} 1 \mathrm{~N}$ sebanyak $\pm 4 \mathrm{~mL}$ sampai $\mathrm{pH}$ larutan 7-8. Tunggu sesuai OT yang didapat sebelumnya. Kemudian tambahkan Aquadest 7 $\mathrm{mL}$ dan baca larutan di spektrofotometer visible pada panjang gelombang maksimal yang didapat (747,2 nm). Buat kurva hubungan Konsentrasi Vs absorbansi, untuk kemudian ditentukan persamaan regresi liniernya.

\section{Penetapan Kadar Glukosa Ubi Cilembu dengan metode Somogyi-Nelson (Nelson, 1944)}

Penentuan kadar sampel dilakukan dengan menambahkan $1 \mathrm{~mL}$ larutan ekstrak sampel konsentrasi 1,0 mg/mL. Pembacaan kadar glukosa ubi Silembu dilakukan dengan menambahkan 1 mL larutan ekstrak sampel konsentrasi $1,0 \mathrm{mg} / \mathrm{mL}$ dengan 1,0 $\mathrm{mL}$ reagen $\mathrm{Cu}$ alkalis (Campuran reagen Nelson A dan B). Kemudian larutan digojok dan larutan dipanaskan di atas waterbath dengan suhu $100^{\circ} \mathrm{C}$ selama 20 menit. Kemudian larutan digojok dan larutan dipanaskan kembali di atas waterbath dengan suhu $100^{\circ} \mathrm{C}$ selama 10 menit. Larutan ditambah $\mathrm{NaOH} 1 \mathrm{~N}$ sebanyak $\pm 4 \mathrm{~mL}$ sampai $\mathrm{pH}$ larutan $7-8$. Tunggu sesuai OT yang didapat sebelumnya. Kemudian tambahkan
Aquadest $7 \mathrm{~mL}$ dan baca larutan di spektrofotometer visible pada panjang gelombang maksimal yang didapat $(747,2 \mathrm{~nm})$.

\section{Uji Validasi}

Uji Linealitas

Uji linearitas dilakukan dengan membuat larutan standar glukkosa dengan rentang konsentrasi 0,$025 ; 0,03 ; 0,035 ; 0.04 ; 0,045 ; 0,05$; $0,055(\mathrm{mg} / \mathrm{mL})$ kemudian ditambah pereaksi sesuai prosedur,masing-masing metode dibaca absorbansi pada lambda yang sesuai. Dibuat persamaan regresi linear antara konsentrasi vs absorbansi, tentukan slope, intersep dan koefisien korelasi (r)

\section{LOD dan LOQ (Harmita et al, 2004)}

Penentuan LOD dan LOQ dilakukan dengan Batas deteksi dan kuantitasi dapat dihitung secara statistic melalui garis regresi linier dari kurva kalibrasi. Nilai pengukuran akan sama dengan nilai $\mathrm{b}$ pada persamaan garis linier $\mathrm{y}=\mathrm{a}+\mathrm{bx}$, sedangkan simpangan baku blanko sama dengan simpangan baku residual (Sy/x.)

$$
\begin{aligned}
& \text { Batas deteksi (Q) } \\
& \mathrm{Q}=\frac{3 \mathrm{Sy} / \mathrm{x}}{\mathrm{Sl}}
\end{aligned}
$$

Batas kuantitasi (Q)

$$
\mathrm{Q}=\frac{10 \mathrm{Sy} / \mathrm{x}}{\mathrm{S} 1}
$$

\section{Uji Ketelitian (RSD)}

Uji ketelitian dilakukan dengan menentukan RSD dari replikasi penentuan kadar gula pereduksi dalam ubi pada kedua metode.

\section{Uji Akurasi (recovery)}

Uji akurasi dilakukan dengan metode spiking. Pada metode Somogyi-Nelson uji recovery menggunakan $0,5 \mathrm{mg} / \mathrm{mL}$ konsentrasi sampel dan $0,05 \mathrm{mg} / \mathrm{mL}$ konsentrasi standar, serta campuran keduanya. Sama halnya pada uji recovery menggunakan $0,1 \mathrm{mg} / \mathrm{mL}$ konsentrasi sampel dan 
0,02 $\mathrm{mg} / \mathrm{mL}$ konsentrasi standar serta campuran keduanya.

\section{HASIL DAN PEMBAHASAN \\ Determinasi Tanaman}

Tanaman ubi Cilembu yang digunakan pada penelitian ini berasal dari desa Citali, Sumedang, Jawa Barat. Identifikasi tanaman dilakukan untuk menghindari kesalahan dalam pengambilan tanaman serta memastikan dan mendapatkan kebenaran identitas dari tanaman yang diteliti yaitu ubi jalar (Ipomea batatas L.) Cilembu jenis Rancing. Identifikasi terhadap tanaman dilakukan di Laboratorium Biologi Fakultas Matematika dan Ilmu Pengatahuan Alam Universitas Ahmad Dahlan Yogyakarta. Hasil identifikasi menunjukan bahwa tanaman yang digunakan dalam penelitian ini adalah benar ubi jalar (Ipomea batatas L.) Cilembu jenis Rancing.

\section{Standarisasi Simplisia}

Standarisasi simplisia dilakukan untuk menjamin mutu simplisia yang akan digunakan dalam penelitian kali ini. Standarisasi yang dilakukan pada penelitian ini meliputi 5 uji yaitu, uji organoleptis, uji kadar abu total, uji kadar air, dan uji susut pengeringan. Hasil parameter mutu bisa dilihat pada Tabel I. Hasil standarisasi simplisia yang didapat memenuhi semua persyaratan mutu simplisia, sehingga dapat ditarik kesimpulan bahwa simplisia memenuhi syarat mutu secara fisika dan kimia.

\section{Hasil Uji Kualitatif Gula pereduksi dalam Ubi Cilembu}

Uji kualitatif ini bertujuan untuk membuktikan ada tidaknya gula pereduksi (khususnya glukosa) pada sampel ubi Cilembu, serta mengetahui gula apa saja yang terdapat didalam ekstrak ubi Cilembu. Uji yang dilakukan meliputi uji Molisch, uji Barfoed, uji Benedict, dan KLT menggunakan sampel berupa ekstrak cair ubi Cilembu. Pada Tabel II ditampilkan hasil dari uji-uji kualitatif. Hasil uji KLT tersaji pada Gambar 1.

Didapatkan nilai Rf masing-masing standar, yaitu glukosa 0,288, fruktosa 0,325, Laktosa 0,088 , sukrosa 0,163 , dan galaktosa 0,255 . Hasil elusi dari ketiga sampel terlihat adanya kandungan dari glukosa, sukrosa, galaktosa dan fruktosa, namun tidak untuk laktosa. Hal ini didukung oleh nilai Rf dari sampel yang sama dan hampir mendekati nilainya dengan Rf standar.

Berdasarkan hasil uji kualitatif yang dilakukan dapat ditarik kesimpulan bahwa sampel ubi Cilembu secara umum mengandung gula pereduksi golongan monosakarida. Dan secara khusus ubi Cilembu mengandung glukosa dan gula-gula lain. Hasil ini menunjukkan bahwa ekstraksi sampel yang dilakukan belum cukup spesifik dalam menyari glukosa saja.

Tabel I. Hasil Parameter Mutu Simplisia

\begin{tabular}{clll}
\hline Parameter & Komponen Mutu & Tepung Ubi & Persyaratan \\
\hline \multirow{5}{*}{ Fisika } & Rasa & Anyep & Anyep \\
& Bau & Khas Tepung (Normal) & normal \\
& Warna & Putih Kekuningan & Putih kekuningan \\
& Bentuk & Serbuk & Serbuk \\
& Kehalusan (Lolos ayakan no 80.) & Sangat Halus (97\%) & Min. 90\% \\
\hline \multirow{2}{*}{ Kimia } & Abu Total (\%) & $3,92 \pm 0,658$ & $<4,71 \%$ \\
& Kadar Air (\%v/b) & $7,72 \pm 2,889$ & $<10 \%$ \\
& Susut Pengeringan $(\%)$ & $7,47 \pm 3,603$ & $<10 \%$ \\
\hline
\end{tabular}

Tabel II. Hasil Uji Kualitatif Ubi Cilembu

\begin{tabular}{lll}
\hline \multicolumn{1}{c}{ Uji Kualitatif } & \multicolumn{1}{c}{ Hasil } & \multicolumn{1}{c}{ Keterangan } \\
\hline Uji Molisch & $(+)$ Gula / Karbohidrat & Terbentuk Cincin berwarna Ungu \\
Uji Benedict & $(+)$ Gula Pereduksi & Terbentuk Endapan Merah Bata \\
Uji Barfoed & $(+)$ Monosakarida & Endapan Terbentuk Dengan Cepat \\
Kromatografi Lapis Tipis & $(+)$ Glukosa & Terdapat Juga Fruktosa, Sukrosa, dan Galaktosa \\
\hline
\end{tabular}




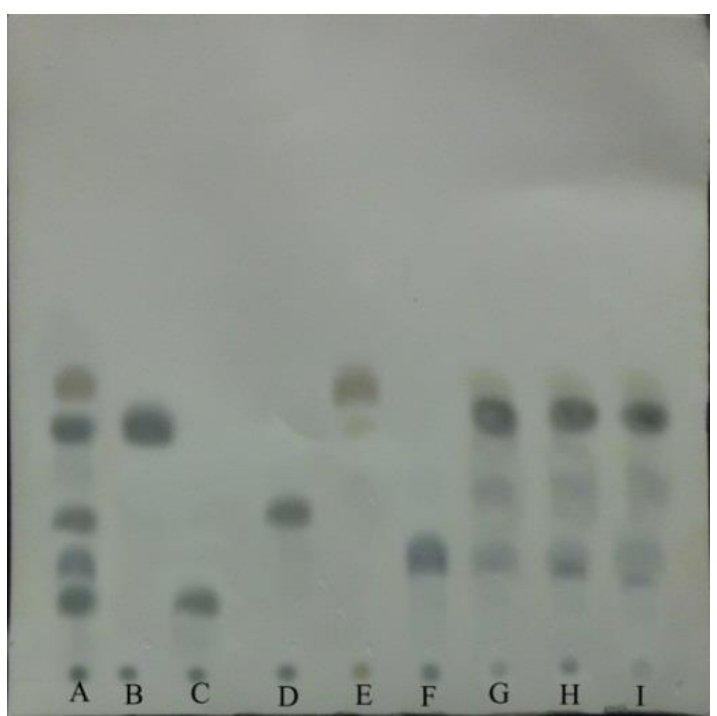

Gambar 1. Hasil KLT Campuran standar glukosa, sukrosa, fruktosa, laktosa, galaktosa (A), Glukosa (B), Laktosa (C), Galaktosa (D), Fruktosa (E), Sukrosa (F), Sampel replikasi 1 (G), Sampel Replikasi 2 (H), Sampel Replikasi 3(I); dengan fase diam plat silica gel G; fase gerak etil asetat-isopropanol-air-piridin (26:14:10:2, v/v); penampak: bercak anilin-difenilamin

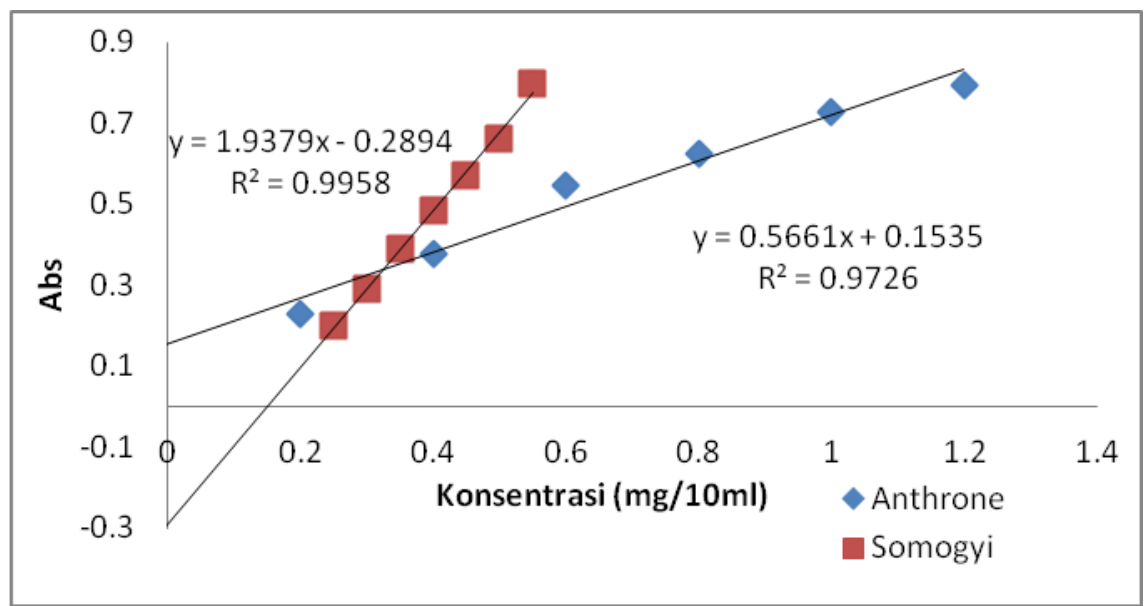

Gambar 2. Kurva hubungan antara konsentrasi standar glukosa vs absorbansi

\section{Hasil Uji Kuantitatif}

Waktu operasional ditentukan dengan mengukur hubungan antara waktu pengukuran dengan absorbansi larutan, Hasil penelitian menunjukkan OT pada metode Somogyi-Nelson adalah menit ke-21-34. Sementara pada metode Anthrone adalah menit ke6-16. Hasil penentuan panjang gelomang maksimum diperoleh $747,2 \mathrm{~nm}$ pada metode Somogyi-Nelson dan 623,8 untuk metode Anthrone-sulfat.

Kurva hubungan antara konsentrasi standar dan absorbansi glukosa pada kedua metode tersaji pada Gambar 2.

\section{Penetapan Kadar Gula Pereduksi}

Analisa dilakukan selanjutnya adalah membandingkan hasil penetapan kadar antara 
metode Somogyi-Nelson dengan metode AnthroneSulfat. Berikut ditampilkan hasil penetapan kadar metode Somogyi-Nelson dengan metode AnthroneSulfat pada Tabel III. Dari perhitungan dengan metode Somogyi-Nelson didapatkan nilai kadar glukosa ubi Cilembu yaitu 3,42 $\pm 0,127(\% \mathrm{~b} / \mathrm{b})$. Berdasarkan kadar yang didapat, pada 5 gram simplisia yang gunakan dalam ekstraksi terdapat glukosa sebanyak 0,1798 gram.

Dari perhitungan didapatkan kadar glukosa ubi Cilembu dengan metode Anthrone-Sulfat yaitu $14,99 \pm 1,29(\% \mathrm{~b} / \mathrm{v})$. Berdasarkan kadar yang didapat, pada 5 gram simplisia yang digunakan dalam ekstraksi terdapat glukosa sebanyak 0,7497 gram.

Tabel III. Tabel Perhitungan Perbandingan Kadar Gula Pereduksi Bedasarkan Metode Somogyi-Nelson dan Anthrone

\begin{tabular}{ccc}
\hline Rep. & \multicolumn{2}{c}{ Kadar (\%) } \\
\hline & Somogyi-Nelson & $\begin{array}{c}\text { Anthrone- } \\
\text { sulfat }\end{array}$ \\
\hline $\mathbf{1}$ & 3,24 & 16,33 \\
$\mathbf{2}$ & 3,31 & 14,74 \\
$\mathbf{3}$ & 3,39 & 15,63 \\
$\mathbf{4}$ & 3,37 & 15,80 \\
$\mathbf{5}$ & 3,46 & 13,33 \\
$\mathbf{6}$ & 3,59 & 13,15 \\
$\mathbf{7}$ & 3,55 & 15,98 \\
\hline Rata-rata & 3,42 & 14,99 \\
SD & 0,127 & 1,29 \\
CV & 3,73 & 8,63 \\
\hline
\end{tabular}

Berdasar Tabel III terlihat perbedaan yang sangat jauh, lebih besar kadar yang diperoleh dengan metode anthrone dari pada kadar dengan metode Somogyi-Nelson. Terjadinya peredaan yang signifikan dikarenakan metode AnthroneSulfat merupakan metode untuk menguji kadar gula total, dimana reaksi furfuralasi antara asam kuat tidak hanya terjadi atau bereaksi dengan gula pereduksi saja namun juga dengan gula-gula non pereduksi.. Metode Anthrone-Sulfat merupakan salah satu contoh metode kolorimetri untuk menetapkan konsentrasi dari gula total yang ada disampel. Gula akan bereaksi dengan reagen Anthrone dalam kondisi asam yang akan membentuk warna biru-kehijauan. Sampel akan bercampur dengan asam sulfat dan reagen Anthrone dengan bantuan pemanasan. Larutan kemudian didinginkan dan dibaca pada absorbansi $630 \mathrm{~nm}$. Ada hubungan linier antara absorbansi yang terbaca dengan jumlah gula yang ada di dalam sampelnya. Metode ini akan menetukan gula pereduksi dan gula non pereduksi karena adanya $\mathrm{H}_{2} \mathrm{SO}_{4}$ sebagai oksidator yang sangat kuat (Dreywood, 1946). Jadi dalam hasil dimungkinkan yang terbaca bukan hanya glukosa, tapi juga gula-gula lain yang ada didalam ekstrak sampel, seperti sukrosa. Dreywood (1946) melakukan uji spesifisitas dari reaksi dan membuat daftar 18 jenis karbohidrat, termasuk beberapa turunan selulosa, yang memberikan hasil positif.

Lain halnya dengan metode Somogyi-Nelson, dimana reaksi yang terjadi antara reagen cu alkalis $\left(\mathrm{Cu}^{2+}\right)$ spesifik dengan gula pereduksi menjadi $\mathrm{Cu}^{+}$(endapan merah bata) kemudian ketika ditambahkan arsenomolibdat endapan tersebut akan larut dan membentuk kompleks $\left[\mathrm{AsMo}_{4}{ }^{\mathrm{V}} \mathrm{Mo}_{8}{ }^{\mathrm{VI}} \mathrm{O}_{40}\right]^{7-}$ berwarna biru kehijauan $\left(\mathrm{Cu}^{+}\right.$diubah kembali menjadi $\left.\mathrm{Cu}^{2+}\right)$. Oleh sebab itu, gula - gula lain non pereduksi yang ada didalam sampel tidak akan mempengaruhi reaksi yang terjadi. (Kautsar, 2011). Intensitas warna yang terbentuk menunjukkan banyaknya gula pereduksi yang terdapat dalam contoh, hal tersebut karena konsentrasi arsenomolibdat yang tereduksi sebanding dengan konsentrasi tembaga (1) oksida $(\mathrm{Cu} 2 \mathrm{O})$, sedangkan konsentrasi $\mathrm{Cu} 2 \mathrm{O}$ sebanding dengan konsentrasi gula pereduksi (Nelson, 1944). Pada teknik spektrofotometri ini, analisis dari sejumlah mono- dan disakarida hanya dapat menggambarkan kadar gula pereduksi (Hart and Fischer, 1972).

\section{Analisis Data Perbandingan Metode (Uji Validasi)}

Perbandingan metode dilakukan dengan melakukan uji validasi terhadap 2 metode yang akan dibandingkan, yaitu metode Somogyi- 
Nelson dengan metode Anthrone-Sulfat. Dimana uji validasi yang dilakukan meliputi 5 uji, yaitu uji kepekaan, uji ketepatan, uji ketelitian, liniertias dan selektivitas. Pada Tabel IV. akan ditampilkan hasil perbandingan uji validasi metode Somogyi-Nelson dengan metode Anthrone-Sulfat.

Tabel IV. Perbandingan Hasil Uji Validasi Metode

\begin{tabular}{c|cc}
\hline Uji Validasi & $\begin{array}{c}\text { Somogyi- } \\
\text { Nelson }\end{array}$ & $\begin{array}{c}\text { Anthrone- } \\
\text { Sulfat }\end{array}$ \\
\hline LOD (mg/mL) & 0,00167 & 0,01980 \\
LOQ (mg/mL) & 0,00557 & 0,06600 \\
\%Recovery (\%) & $90,285 \pm 16,1$ & $74,677 \pm 8,98$ \\
RSD (\%) & 3,7 & 8,6 \\
Slope (b) & 1,9378 & 0,5661 \\
Selektivitas & & Kurang \\
(Terhadap Gula & Selektif & Selektif \\
Pereduksi) & & \\
\hline
\end{tabular}

Pada Tabel IV. dapat dilihat hasil uji kepekaan menunjukkan bahwa metode Somogyi-Nelson memiliki memiliki kepekaan yang lebih tinggi dibandingkan metode Anthrone-Sulfat, terlihat dari nilai LOD LOQ Somogyi-Nelson berturut-turut $1,67 \times 10^{-3}$ dan $5,57 \times 10^{-3}$ lebih kecil nilainya dibandingkan nilai LOD LOQ Anthrone-Sulfat yaitu $1,98 \times 10^{-2}$ dan $6,6 \times 10^{-2}$.. Hal ini diperkuat dengan nilai slope untuk metode Somogyi-Nelson $(1,9378)$ lebih besar dari pada slope pada metode Anthrone-sulfat (0,5661) Hasil uji ketelitian menunjukkan metode Somogyi-Nelson lebih teliti, terlihat dari nilai RSD metode Somogyi-Nelson yang jauh lebih baik karena 3,7\% < 5\% dengan metode Anthrone-Sulfat $(8,73 \%>5 \%)$. Hasil uji ketepatan metode Somogyi-Nelson memenuhi persyaratan farmakope (> 90\%) dan nilainya lebih besar dibanding metode Anthrone-Sulfat yang menunjukkan ketepatan metode Somogyi-Nelson lebih baik. Untuk linieritas dan selektivitas metode Somogyi-Nelson juga lebih baik.

Dari hasil yang didapat, metode SomogyiNelson memiliki keunggulan dalam semua uji validasi yang dilakukan dibanding metode Anthrone-Sulfat, sehingga bisa ditarik kesimpulan bahwa metode Somogyi-Nelson lebih disarankan untuk digunakan dalam penetapan kadar gula pereduksi ubi Cilembu dibandingkan metode Anthrone-Sulfat.

\section{KESIMPULAN}

Berdasarkan hasil penelitian yang telah dilakukan, dapat ditarik kesimpulan sebagai berikut: Kadar Gula pereduksi pada ubi Cilembu dengan metode Somogyi-Nelson adalah 3,42\% \pm 0,123 . Hasil validasi metode didapatkan berturutturut nilai recovery $=99,8 \%, \mathrm{LOD}=1,67 \times 10^{-3}$ $(\mathrm{mg} / \mathrm{mL}), \mathrm{LOQ}=5,57 \times 10^{-3}(\mathrm{mg} / \mathrm{mL})$, nilai RSD $=3,7 \%$. Kadar Gula pereduksi pada ubi Cilembu dengan metode Anthrone-Sulfat adalah 14,9\% \pm 1,253. Hasil validasi metode didapatkan berturutturut nilai recovery $=74,7 \%$, LOD $=1,98 \times 10^{-2}$ $(\mathrm{mg} / \mathrm{mL}), \mathrm{LOQ}=6,6 \times 10^{-2}(\mathrm{mg} / \mathrm{mL})$, nilai RSD $=$ $8,6 \%$. Hasil dari penelitian ini menunjukkan bahwa metode Somogyi-Nelson lebih disarankan digunakan untuk menganalisa gula pereduksi karena nilai Recovery, LOD LOQ dan nilai RSDnya lebih baik dibanding dengan metode Anthrone-Sulfat.

\section{DAFTAR PUSTAKA}

Anonim, 1999. Official Methods of Analysis of Association Of Analytical Communities International 16th ed, Gaithersburg.

Anonim, 2008. Farmakope Herbal Indonesia, Edisi I. Departemen Kesehatan Republik Indonesia, Jakarta, 4-6, 168-171,

Ambarsari., Indrie, S., and Choliq A., 2009. Rekomendasi Dalam Penetapan Standar Mutu Tepung Ubi Jalar. Balai Pengkajian Teknologi Pertanian (BPTP), Jawa Tengah.

Dreywood, R., 1946. Qualitative test for carbohydrate material. Journal Industrial \& Engineering Chemistry Analytical Edition, 18, 499-499.

Hart, A.M.L., and Fischer, H.J., 1972. Modern Food Analysis. Journal Springler Verlag.

Koehler, L.H., 1952. Differentiation of carbohydrates by anthrone reaction rate and color intensity. Journal Analytical Chemistry, 24, 1576-1579.

Mayastuti, A., 2002. Pengaruh Penyimpanan dan Pemanggangan Terhadap Kandungan Zat Gizi 
dan Daya Terima Ubi Jalar (Ipomea batatas (L.) Lam) Cilembu. Skripsi, Fakultas Gizi Masyarakat dan Sumberdaya Keluarga, Institute Pertanian Bogor, Bogor.

Nelson, N., 1944. A photometric adaptation of the Somogyi method for the determination of glucose. Journal Biol. Chem, 153(2), 375-379.
Poedjiadi, A., and Supriyanti, F.M.T., 2009. Dasar - Dasar Biokimia. Penerbit UI Press, Jakarta, 39-42.

Zhang, D.P., Wheatley, Z., Corke, C.C., and Harold, 2002. Biochemical changes during storage of sweet potato roots differing in dry matter content. Postharvest Biology and Technology, 24 (3), 317-325. 